\begin{abstract}
Iranica
Abstracta Iranica Revue bibliographique pour le domaine irano-aryen

Volume 34-35-36 | 2017

Comptes rendus des publications de 2011-2013
\end{abstract}

\title{
Bruce Wannell, Wahid Amini. Kabul Elite Burials. A wounded heritage.
}

\section{Sandra Aube}

\section{(2) OpenEdition}

Journals

\section{Édition électronique}

URL : http://journals.openedition.org/abstractairanica/41250

DOI : 10.4000/abstractairanica.41250

ISSN : 1961-960X

Éditeur :

CNRS (UMR 7528 Mondes iraniens et indiens), Éditions de l'IFRI

\section{Référence électronique}

Sandra Aube, "Bruce Wannell, Wahid Amini. Kabul Elite Burials. A wounded heritage. », Abstracta Iranica [En ligne], Volume 34-35-36 | 2017, document 6, mis en ligne le 15 juillet 2016, consulté le 27 septembre 2020. URL : http://journals.openedition.org/abstractairanica/41250 ; DOI : https://doi.org/ 10.4000/abstractairanica.41250

Ce document a été généré automatiquement le 27 septembre 2020.

Tous droits réservés 


\title{
Bruce Wannell, Wahid Amini. Kabul Elite Burials. A wounded heritage.
}

\author{
Sandra Aube
}

\section{RÉFÉRENCE}

Bruce Wannell, Wahid Amini. Kabul Elite Burials. A wounded heritage. Kaboul, Aga Khan Trust for Culture, 2013, 140 p., ill. couleur, anglais et dari.

1 Cet ouvrage résulte d'un programme de conservation conduit entre 2002 et 2010 par le Historic Cities Programme of the Aga Khan Trust for Culture. Il parait la même année que son pendant: Herat Elite Burials. An endangered heritage, écrit par les mêmes auteurs (Kaboul, AKTC, 2013). Si aucun de ces deux livres ne suit une démarche historique, ils s'avèrent constituer néanmoins deux outils utiles pour l'étude des monuments funéraires et de l'épigraphie, dans la mesure où ils proposent un matériel jusqu'alors largement inédit.

2 Ce livre propose effet un catalogue de 35 tombes en pierre sculptée à décor épigraphique conservées à Kaboul (Bāg̀-e Bābor, mausolée de Tīmūr Šāh et alentours d'Āšeqān va 'Ārefān). Le catalogue est classé chronologiquement, depuis la période moghole (chapitre 1, p. 10-35: "Mughal and Sadozai, 1567-1805 »), jusqu'à la fin du $\mathrm{XIX}^{\mathrm{e}}$ s., plus largement représentée (chapitre 2 : « Barakzai, 1828-1882 », p. 36-99).

Chaque entrée propose une très courte description de la tombe étudiée, suivie d'une retranscription complète des inscriptions en persan, qui ne sont cependant pas traduites en anglais. Ces inscriptions sont généralement accompagnées de photographies de bonne qualité, permettant d'en vérifier au besoin la transcription.

Le troisième chapitre rend compte d'interviews conduites en 2010 sur des sculpteurs, fossoyeurs, ou même sur des habitants du secteur d'Āšeqān va 'Ārefān. Suit enfin une série d'annexes : catalogue des stèles, glossaire, clés d'interprétation des dates en abjad, un tableau méthodologique pour l'enregistrement des tombes, puis une liste des 
prières, versets coraniques utilisés, et des poèmes persans employés (en persan uniquement). Aucune bibliographie n'est proposée.

\section{AUTEURS}

\section{SANDRA AUBE}

CNRS, Mondes iranien et indien, Paris 